\title{
Adaptive Return of e-Training (ROT) based on Communication Technology
}

\author{
Fahad Alotaibi \\ Department of Information System \\ Faculty of Computing and Information Technology, \\ King Abdulaziz University, \\ Jeddah, Saudi Arabia
}

\begin{abstract}
Persistent economic insecurity and harsh severity actions across the world push businesses either to cut down on training costs or to be very painstaking in choosing a training program that conveys palpable outcomes in a short period of time. Nevertheless, in most cases businesses are still unable to reckon Return of e-Training (ROT) in advance for better allocation of training budget and decision on a proper training plan in line with the business policy. The purpose of this paper is to appraise the practical worth of the applicability and usability of the Adaptive ROT in the enterprises with a particular regard to evaluating the impact of e-training in companies. A case study of gauging the profit of e-training in the Blackboard systems has been conducted. The outcome of this study is judged to be positive, given the efficacy of the Adaptive ROT Evaluation Model for e-training in companies.
\end{abstract}

Keywords-Return of e-Training (ROT); evaluation models; blackboard; e-learning; Key Performance Indicator (KPI)

\section{INTRODUCTION}

Smart Learning and Development (L\&D) groups are busy defining the factors that people consider in their prioritizations, by demonstrating the prolific effort of their labor force [1]. Motivating workforces to make use of technology is a big controversial issue, given their weak enthusiasm to get familiar with L\&D for learning [6], [12]. Actually, they want to better their job-related skill sets to improve their career prospects. In this framework, this inclination to better their individual performance through the use of technology is called "learning" [8], [22]. Identifying this drive in the employee is vital to teaching technology, by guaranteeing micro (individual goal) and macro (organizational goal) development. Although companies are aware of the significance of training of their personnel, they still calculate the financial gains too.

Organizations downturn forced management to analyze the profit of training, taking into account the financial portions within their monetary restraint [5], [7], [8], [10]. Skill sets have sufficiently proven that the adoption of technology and training can function properly if businesses ascertain that they can make profits in case they opt for training and accept as true that novelty in tools of assessment and processes is unavoidable. A wide-ranging and inexpensive ROT system must adopt business strategic practices. By developing an ROT system that is reasonably priced and comprehensive, and is an outcome of strategic business planning, the quality and efficacy of training can increase [10], [23]-[26].

This emphasis on ROT denotes the new-found focus put on the improvement of the professional practices by internal and external trainers.

\section{Methodology}

In this study, the methodology of adaptive ROT system, based on collaboration and use of communication technology, has a block diagram as shown in Fig. 1.

The study consists of four (4) major sections: 1) Measuring the training by using KPI, 2) Adapting employees with e-learning, 3) Measuring ROT, and 4) Measuring the time period of ROT.

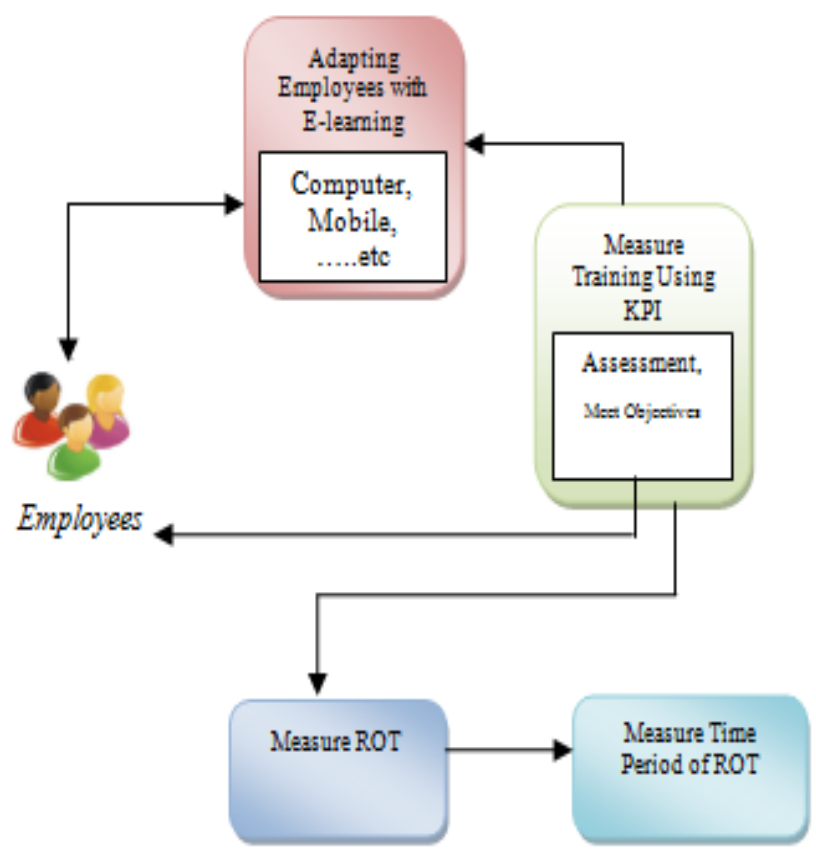

Fig. 1. The framework of adaptive ROT.

This Research Project is sponsored by the Deanship of Scientific Research (DSR)-King Abdulaziz University -Jeddah-Saudi Arabia 


\section{MEASURING AND BENCHMARKING TRAINING PROGRAMS OUTCOMES USING KPI}

Management usually has unclear understanding of ROT, and, quite often, it is not conscious of training costs. For this reason, it is not surprising that educational programs become the first victim of cost-reduction campaigns when a business faces a depression.

It follows then that training and organization development manager has to take the following actions to make sure that ROT will measure the employee's performance [8], based on managing by objective system for the company: (1) He has to base the policy of training needs assessment on the following necessary factors: (1.1) The annual performance results based on 90 degrees system at least, (1.2) an updated Job description, (1.3) The updated changes in the annual overall operation plan for the company, and (1.4) the results of suggestions system. (2) He has to design the training courses and outlines in order to cover the reality means, depending on the cost center policy for each department, which forces the department manager to ponder on what exact needs for the department to achieve within the estimated yearly expenses. (3) He has to divide the training activities between the external training and internal training (on-job training) to guarantee that the following things take place: (3.1) First, the business needs to gain new experience from the external training to its personnel, (3.2) Then, they need to use internal training and On-the-Job Training (OJT) to make them transfer what they learned from the external training to their colleagues (to make sure that all are on the same page and none has a rare experience). (4) Before every training course, the business has to write a report on the training needs and hand it to the instructor; regularly assess (together with the instructor) the way of implementing the training in the real life by a final daily training report; and the trainees have to sign with knowledge. (5) One month after the end of the each course, the training manager should visit the department which got the course, consider whether they implemented the training by the signed report or not, and measure the ROT.

\section{ADAPTING EMPLOYEES FOR E-LEARNING TECHNOLOGY}

Familiarizing the employees with e-learning technologies can be achieved by following five tips as stated in [9], [13], [26]. These tips can work for peers in other organizations and help to accomplish the L\&D objectives, by utilizing the appropriate technologies. Below are these tips:

- Address Your Employee's Biggest Work Challenges: One should collect his employees' specific work challenges. What to do with them will be explained in the 4th tip, but to summarize, one can say that the adoption of the right technology and approach means one can specifically address these challenges without any problem of technology use at all. Client experiences are becoming more personalized-deviating from standardization - as they are facilitated by smart technology, and consumer expectations are also becoming associated with corporate expectations.

- Don't Dress up HR and L\&D Priorities as Employee Priorities: On a common-sense level, managers should have access to it. But what are the company primacies that are inhibiting the managers from having access to it? Their world is intricate and challenging, and so considering what could be seen as supplementary (nonbusiness critical) activities as priority is unrealistic. Very often, an incongruity of primacies (between HR and employees themselves) originates from interest conflicts. So, one should get close to them and comfort them with their insistent distresses (their 'what?')-and he might just find ways to impact the 'how?'

- Share Career Stories of How others Have Progressed: One should gather as many job stories as he can of individuals in his company across diverse ranks, functional disciplines, and development in the organization. Host panel events to enhance his video stories, and thus participate in dialogues and bring them to life.

- Use 'Resources' to Keep Employees in the Workflow: The objective is to provide just enough perception, instruction, or information to aid the workers to advance with their work, with the addition of more selfreliance and proficiency than they would without it. This would be done with the appropriate technology, such as Loop (which is goal-oriented for your assets). Bear in mind that the user's know-how is as important as the presented content. If a resource can't be accessed on-demand, on-the-go, and as simply as a web-search, then Google would win! The appropriate tools make all the variance. Moreover, numerical resources can be created and shared in seconds, with Loop. So, one should not cut corners; he should rather spend on the suitable utensils.

- Run Campaigns to Drive Traffic and Repeat Visits: Unluckily, we don't live in 'Field of Dreams' (or Wayne's World 2) and if we construct that world, dreams will not come. We have to conduct operations to trade the worth of your assets and guarantee unrelenting commitment. Even YouTube has weekly summaries of their most watched videos in order to sustain commitment. One's own weekly summaries can be produced and shared for the sake of energy circulation and repeated visits; and one can also generate worker stories that prove the worth of committing time to his resources through the upshots that can be attained. One has to be insightful and make use of the best weekly summaries out there, just because his content will not do this on its own. He can achieve that in an easy way by showing what's popular and showing what's new.

\section{A. Advantages of e-Learning}

Many companies have made investments in e-Learning over the last twenty years, principally for the following advantages:

- Self-paced, interactive, and more appealing learning (from learner perspective).

- Access at any time, and from anywhere (on-demand availability). 
- Cost-effective (particularly when the training is delivered to a large audience).

- Less troublesome conveyance (in contrast to ILT).

- Easy tracing of learner's advancement and accomplishment (from business perspective).

- Message-consistency and easy content- updating.

\section{B. Measuring Return on Investment( ROI) of Online Training}

The adoption of e-learning is gaining further impetus, because traditional e-Learning moves towards mobile learning or m-Learning and provides learners with the flexibility of learning on the device of their choice (notably tablets and smart phones) [18]-[22]. E-learning and m-learning provide several paybacks to establishments. Nonetheless, the emphasis is now shifting to determining its influence and the Return On Investment (ROI) of online training. A successful e-learning inventiveness must be capable of bringing gains that are more than the expenses [17]. ROI is the return on investment that a business achieves, and can be calculated as:

\section{ROTI $=$ Gain or Return $/$ Cost}

It may be calculated by way of two parameters, specifically the expenses paid out (or charge suffered) and the Worth/Achievement amassed (or return).

Calculating Return on Training Investment (ROTI): Return on Investment (ROI) is the correlation between monetary paybacks acquired from something (in this case a learning program) and the overall budget of that thing. The objective of an ROI scrutiny is mostly to assess whether the profits are greater than the expenses, i.e. to perceive whether the expenses were worth it. It is worth noting that ROI of learning can only be measured reliably by means of Training Check, if the conditions below are fulfilled: (1) Availability of trustworthy information on variations to related organization performance measures (to be reasonably estimated by key stakeholders). (2) Possibility of assigning financial value Changes to the selected performance measures [8], [22]. (3) Identification of the expenses related to the development, delivery and management of the learning. If these conditions are fulfilled, one can use Training Check to prepare a Returnon-Training Investment (ROTI) report, by means of the ROTI Calculator function, and by following the stages below. Once the relevant financial data have been entered, the Calculator will routinely compute the ROTI \% such as below:

$$
R O T I=\frac{£ \text { BENEFITS }-£ \text { COSTS }}{£ \text { COSTS }} \times 100 \%
$$

The Benefit to Cost ratio will also be calculated as follows:

$£$ BENEFITS : £ COSTS, as stated in [2-5]. There is also another possibility to determine the 'Payback Period', i.e. the time it takes to reimburse the expenses. Remarks on ROTI Outcomes: It is worthwhile to get primary arrangement from learning program supporters regarding the objective level of ROTI. As a customary norm, ROTI levels beneath about $20 \%$ are generally assessed to be low. In reality, however, it is reasonably customary for ROTI ratio records to be very high, example 500\% or more. Although elevated ROTI records may amaze high-ranking executives, they possibly will also nurture suspicions, specifically amongst those who are commonly unimpressed by the significance of on-site-training.

For this reason, it is significant to integrate ROTI computations with other aspects of assessment. Furthermore, demonstrating a constant correlation between the training and advances in career and business accomplishment will boost substantial reliability to ROTI records. Likewise, wherever the ROTI records attained are truncated or undesirable, reaction from other assessment ranks can be used to assist identify any hindering causes.

\section{Calculating Return on Training Investment (ROTI)}

Computing the return on investment from a training program could be significant once the training program is seen as a substantial deal by the organization, or once it is brought into line with the accomplishment of a particular planned or real goal. It could as well be worthwhile once it is unclear if a program will engender any economic returns or what those returns might rise to.

Nonetheless, despite the fact that ROTI might have a significant role in a training program assessment, an ROTI measurement only will not customarily be enough to commend the company situation for a training program or convince high-ranking executives to act in a specific manner. Because of this that very frequently it is only one minor component of the worth of the training. Contingent with the approved goals and anticipations of the training program, factors such as ROTI are very often calculated as follows:

On a regular basis, computing the ROTI from a learning program should only be instigated when the following criteria are met (i.e. in case not all these criteria are met, it follows then that one has to earnestly reflect on if it would be advisable to invest time, energy and assets on making an ROTI investigation):

- The existence of substantial monetary overheads that the learning program requires.

- The ROTI analysis must be meaningful / important to the program's sponsors.

- The training objectives must be plainly well-defined and their attainment must be susceptible to influence on places of the premeditated or effective significance.

- The availability of information on pertinent changes to performance.

- The existence of sufficient trainees to influence the company achievement and draw economic advantages.

- The trainees should be allowed worthy chances to implement their training to the place of work.

- Identification of direct and indirect costs of training.

- Attribution of credible financial values by the main investors to changes to performance (see Note 1 below). 
- Isolation of the training factors from other causes and allocation of the monetary aids in view of that (see Note 2 below).

For instance, if advantages in personnel preservation have yielded an economic profit of $£ 5,000$ to the business, and it is predictable that the learning is accountable for $50 \%$ of the variation in preservation (and the other $50 \%$ being accredited to other causes), it follows then that the total economic profit associated with the learning is computed as $£ 2,500$ (i.e. $£ 5000$ $\mathrm{x} 50 \%$ ). This total is then used as component of the computation of the Return on Training Investment.

Participants need to be motivated to stay on the conventional side at the time they make budgetary approximations. If these estimations are irrationally high, this may harm the reliability of the ultimate ROTI facts.

\section{Measuring Time Period ROTI}

There exist no stable timespan over which one may determine the ROI of a training program [23]-[25]. Some generally utilized instances encompass three points: (1) From three months to twelve months after training has been completed (allows time for the transmit of training to the jobsite). (2) One financial year (audit period)/the period of a product cycle. (3) Average period of target audience employees retention in the company.

TABLE I. AN EXAMPlE OF PAYBACK PERIOD CALCUlATION

\begin{tabular}{|l|l|}
\hline Number of months over which benefits are calculated & $\mathbf{1 2}$ \\
\hline Total Benefits & 81,500 \\
\hline Monthly benefits = & 6,792 \\
\hline Total Costs & 15,000 \\
\hline Payback period & $\mathbf{2 . 2}$ months \\
\hline
\end{tabular}

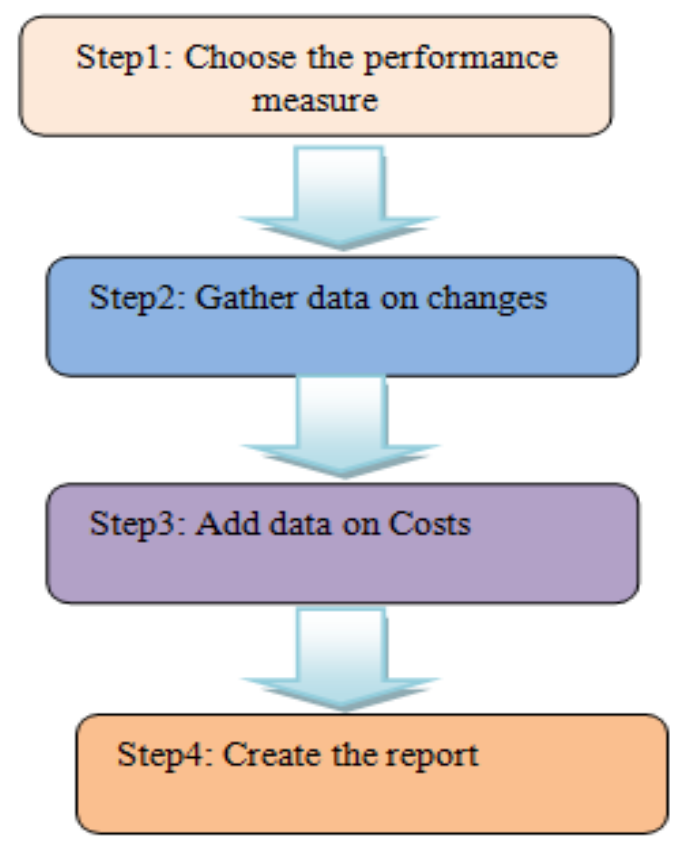

Fig. 2. Stages for collecting ROTI data and creating report.
Definition 1: Payback Period: The Payback Period is the time spent to recompense back the expenses, i.e. when the incurred expenses equal the accrued profits [2]-[6], [14]. A small return timespan is expected to amaze and may add to the company situation for spending on additional learning. The ROTI Calculator computes the return timespan by matching stated paybacks with stated expenses such as indicated in Table I:

\section{Payback Period $=\frac{\text { COSTS }}{\text { monthly benefits }}$}

Gathering ROTI data and creating the ROTI report commonly goes through four fundamental stages, these stages can as presented in Fig. 2 and can be delineated as follows:

Stage 1: The choice of the performance measures to be used. First, one has to work with the main sponsors to select the appropriate corporate performance measures which are meant to be used as a foundation for the ROTI scrutiny. Samples of measures comprise variations in: (1) Client contentment and retention rates / degree of customer dissatisfaction. (2) Output/productivity amounts / sales volumes / worker income amounts. (3) Total of monthly sickabsence days / total of annulled training days/sessions. (4) Depletion rates / non-compliance/ annual misfortunes rate / staffing expenses.

It is essential that the selected measures have the following features: They should be quantifiable, or can be rationally estimated by crucial participants, they should be assigned a financial value by investors, and finally, they should be pertinent, i.e. variations in them should be associated with the learning. (Note: When parameters other than the learning that may impact variations to the chosen measures exist, participants have to approximate the ratio of variation which may be openly associated with each parameter).

Stage 2: Data Collection on variations: Next, one has to collect information on the chosen accomplishment measures. He needs to gather the ensuing data like: Monetary information associated with the variations in accomplishment, and Approximations of the \% impact of the learning on these variations comparative to other potential powers. Let us assume the following parameters:

Total Financial Benefit of Performance Change $=T F B P C$,

Influence of the Training $=I O T$, and

Total Financial Benefit Attributable to the Training = TFBAT then TFBAT can be calculated as:

$T F B A T=T F B P C \times \% I O T$

For instance, if the overall economic profit of perfections in employees' maintenance is $£ 10,000$, and the learning is judged to have been accountable for $50 \%$ of that variation, then we obtain what follows:

$T F B A T=£ 10,000 \times 50 \%=£ 5,000$

This total (i.e. $£ 5,000$ ) will be employed as constituent of the ultimate ROTI computation. 
Stage 3: The addition of information on expenses: Once the economic paybacks from the learning program have been added, then data of the expenses connected with the learning will need to be entered. To start this procedure, we need to click the 'Add Data on Costs' key on the ROTI Calculator page. This will trigger the 'Cost Calculator'. After that we only enter the data of costs as prompted. Expenses connected with a learning program would fit in the comprehensive types underneath: (1) Running / development expenses (e.g. developer costs, design, printing). (2) Conveyance expenses (example, facilitator payments, venue, training resources) / turnout expenses (example, worker-discharge overheads, travel, lodging).

Stage 4: Creation of the report: Once we have entered all of the data on monetary profits and expenses connected with a learning program into the ROTI Calculator, we will be able to write the ROTI report. We simply have to press the 'Create Report' key on the final page of the Cost Calculator. The report has to contain a précis of the paybacks and expenses added, and offer a scrutiny of the ROTI \%, the Benefit to Cost ratio, and the Payback Period. ROTI Reports are put in storage on the My Reports page and can be edited there.

\section{RESULTS AND DISCUSSION}

The assessment of performance in our analysis is measured in terms of the learning results to the enterprise and performance objectives, the adoption of the right learning approach to administer the virtual trainings, the implementation of an effective evaluation approach [7], [11], [17], the cover pushing to knowledge execution, the provision of a podium for cooperation in training (social learning), and the obtainment of user feedback and its use to update our approach. A case study of gauging the profit of electronic training in the Blackboard systems has been conducted in this analysis. Table II displays the assessment of the return of electronic training in the Blackboard systems.

Gauging the return of electronic training in the Blackboard systems can be sketched as follows:

It offers great chances for learners to interact with the syllabus outside the lecture room anywhere and at anytime through this electronic system, which provides the learners with an array of tools to view the content of the scientific resources and interact with them in many methods, in addition to communicating with the instructor and the rest of the learners enrolled in the same course by different electronic devices. It comprises tools and means that empower institution participants to develop dynamic and interactive courses with ease, while managing the content of these courses in a supple and simple manner, so that they can accomplish the daily tasks of the learning process successfully.

This system permits the trainer to develop cohesive electronic courses, make notes / outlines of the material / the required jobs and advertisements, and allows the lecturer to present periodical works, and personally original examinations and results.
TABLE II. THE EVALUATION OF THE RETURN OF ElECTRONIC TRAINING IN THE BLACKBOARD SYSTEMS

\begin{tabular}{|c|c|}
\hline Investment & Calculations \\
\hline Cost of course & $€ 20,000.00$ \\
\hline Number of students & 20 \\
\hline Cost per student & $1,000.00$ \\
\hline \multicolumn{2}{|l|}{ Return - Time Savings } \\
\hline Average total cost of employee per year & $€ \quad 45,000.00$ \\
\hline Average total cost per hour & 25.00 \\
\hline Period of improved performance & 12 \\
\hline Value of time saved & 894.60 \\
\hline \multicolumn{2}{|l|}{ Return - Staff Turnover Savings } \\
\hline Average cost of recruitment $\&$ induction & $€ \quad 6,750.00$ \\
\hline Average cost of other training \& warm-up period & $€ \quad 5,625.00$ \\
\hline Impact on staff turnover as proportion of all benefits & $10 \%$ \\
\hline Value of reduced staff turnover & $1,237.50$ \\
\hline \multicolumn{2}{|l|}{ Summary } \\
\hline Total Investment per student & $1,000.00$ \\
\hline Total Return & $€ \quad 2,132.10$ \\
\hline ROI \% & $113 \%$ \\
\hline
\end{tabular}

The system allows the trainer to make a review of lessons, to remotely conduct assignments and electronic tests for training, or to use the institution computer lab, as well to manage discussions and inquiries with learners, or between them. The instructor can design electronic modules with the incorporation of multimedia and diffusion to learners remotely.

The system offers the advantage of downloading the material for the learner, so that he can follow the learning offline, and enables the instructor to put the curriculum on $\mathrm{CDs}$, and enables the learner to review the material through the mobile phone (Pocket PC). The use of the Blackboard 9.0 learning management system makes it easier for an instructor to craft an online course site without the experience of software development and all the necessary access to the system, and the use of the mouse (point-click) to build its decision and follow the sequential guidelines offered by the system. Therefore, with a little training, organization participants can easily build interactive courses and add many features to enhance the course supplied by the system.

The system offers many tools to accomplish the learning process through the integration of the Blackboard and WebCT systems and the release of Blackboard 9.0, which is powerful and highly efficient in terms of ease of use and training management. This program is also used in the universities (King Abdul-Aziz - Electronic - Princess Nora- AlDammam). 
The Blackboard is an information system for the education management system, and it offers follow-up of learners and observing the efficiency of the educational process in the educational organizations. It entails tools and means that arm institution participants with the ability to build dynamic and interactive decisions very easily, with the management of the content of these courses in a supple and simple manner, and to carry out the daily tasks of the educational process successfully. It can present periodical work, examinations and results on a well-timed basis, and evaluations, whether in the interim or final tests [12], [13], [15], [16].

This system allows direct communication with learners through discussion windows and focused and generalized emails. This system can be linked to other electronic learning systems, and interact with these systems in an integrated manner. It allows the possibility of using the Internet Mail with the possibility of placing files attached to the mail. The system involves the existence of the bulletin board that supports the mathematical symbols, images and PowerPoint files, with the ability of the system to archive these things

\section{CONCLUSION AND RECOMMENDATIONS}

The implementation of an effective evaluation approach helps us to assess whether the learning satisfied the necessary mental degree and was truly able to weld the recognized breach. In this research work, we have proposed an Adaptive ROT, a case study of e-training in the Blackboard systems (for King Abdul-Aziz - Electronic - Princess Nora- AlDammam) has been conducted. We have outlined a worthy method to achieve the efficient return of e-training in the Blackboard that can supplement or complement the e-learning package. Other recommendations that can be considered in achieving efficient return of e-training are by providing a podium for cooperation in training (social learning), and investigation confirms that approximately $20 \%$ of our knowledge ensues from feedback and from watching our workmates in action (mates, seniors, or role models). It is worth noting that just $10 \%$ of knowledge results from official learning. Offering forums for social or casual education will be conducive to learning and can also be utilized to generate real-life stories of accomplishment. We can track down user feedback and use it to bring up-to-date our strategy. In the course of the online progress, we have to gather feedback from target learner groups. This needs to be done as we progress.

\section{ACKNOWLEDGMENT}

This paper was supported by the Deanship of Scientific Research (DSR), King Abdulaziz University. The authors, therefore, acknowledge with thanks to DSR's technical and financial support.

\section{REFERENCES}

[1] Barrett, A \& O'Connell, P.J. (2003) Does Training Generally Work? The Returns on In-Company Training, ESRI: Dublin.

[2] Anderson, SB and Ball, S. The Profession and Practice of Program Evaluation, Jossey Bass, San Francisco 1978.

[3] Anderson, V. Value and Evaluation: from return on investment to return on expectation. Report by University of Portsmouth Business School to CIPD, November 2007.

[4] Bersin, J. The Training Measurement Book: Best Practices, Proven Methodologies, and Practical Approaches. Pfeiffer, 2008.

[5] Birnbrauer, H. (1987). Evaluation techniques that work. Training and Development Journal, July, 53-55.

[6] Bowsher, J. (1990). Making the call on the COE. Training and Development Journal, May, 65-66.

[7] Brinkerhoff, R. O. (1988). An integrated evaluation model for HRD. Training and Development Journal, February, 66-68.

[8] Bumpass, S. \& Wade, D. (1990). Measuring participant performance An alternative. Australian Journal of Educational Technology, 6(2), 99107.

[9] Bushnell, D. S. (1990). Input, process, output: A model for evaluating training. Training and Development Journal, March, 41-43.

[10] Erkut, S. \& Fields, J. P. (1987). Focus groups to the rescue. Training and Development Journal, October, 74-76.

[11] Foxon, M. (1989). Evaluation of training and development programs: A review of the literature. Australian Journal of Educational Technology. 5(1), 89-104.

[12] Hewitt, B. (1989). Evaluation a personal perspective. Training and Development in Australia, 16(3), 23-24.

[13] Kirkpatrick, Donald L. (1994). Evaluating Training Programs: The Four Levels. San Francisco: Berrett-Koehler Publishers.

[14] Lombardo, C. A. (1989). Do the benefits of training justify the costs? Training and Development Journal, December, 60-64.

[15] Newstrom, J. W. (1987). Confronting anomalies in evaluation. Training and Development Journal, July, 56-60.

[16] O'Donnell, J. M. (1988). Focus groups: A habit-forming evaluation technique. Training and Development Journal, July, 71-73.

[17] Poulet, R. \& Moult, G. (1987). Putting values into evaluation. Training and Development Journal, July, 62-66.

[18] Phillips, Jack J. (1994). Measuring Return on Investment: Volume I. Alexandria, VA: American Society for Training and Development.

[19] Phillips, Jack J. (1996). "ROI: The Search for Best Practices." Training \& Development 50 (February) 2:42-47.

[20] Phillips, Jack J. (1997a). Handbook of Training Evaluation. Third Edition. Houston, TX: Gulf Publishing.

[21] Phillips, Jack J. (1997b). Measuring Return on Investment: Volume 2. Alexandria, VA: American Society for Training and Development.

[22] Phillips, Jack J. (1997c). Return on Investment in Training and Performance Improvement Programs. Houston, TX: Gulf Publishing.

[23] Robinson, Dana Gaines and J.C. Robinson. (1989). Training for Impact: How to Link Training to Business Needs and Measure the Results. San Francisco : Jossey-Bass Publishers.

[24] Senge, Peter M. (1990). The Fifth Discipline: The Art and Practice of the Learning Organization. New York, NY: Currency Doubleday. Training. (1996). Industry Report. Vol. 33, no. 10: 36-79.

[25] Weatherby, N. L. \& Gorosh, M. E. (1989). Rapid response with spreadsheets. Training and Development Journal, September, 75-79.

[26] Wigley, J. (1988). Evaluating training: Critical issues. Training and Development, 15(3), 21-24. 